\title{
Innovative technical equipment for weed control in leguminous crops
}

\author{
Eugen Marin ${ }^{1, *}$, Marinela Mateescu ${ }^{1}$, Ioan Roşca $^{2}$, Ana-Maria Andrei ${ }^{2}$, Vasile Jinga $^{2}$ and \\ Marga Grădilă \\ ${ }^{1}$ National Institute of Research-Development for Machines and Installations designed to Agriculture \\ and Food Industry-INMA Bucharest 013813, Romania \\ ${ }^{2}$ Research and Development Institute for Plant Protection-ICDPP Bucharest, 013813, Romania
}

\begin{abstract}
Through its rural development policy, the EU aims to help rural areas cope with the many economic, social and environmental challenges that the 21 st century brings. Weeds are a major scourge for farmers who cultivate organic leguminous crops in rural areas, which often have to invest in many weed control methods in order to increase crop yields. The paper presents innovative technical equipment for weed control through a process involving the blasting of young weeds with small fragments of organic material by means of air compressor and granular material distribution system that degrades in depth both the strain and the leaves of the weeds. Organic materials that can be used in weed blasting are walnut shells, granulated corn cobs, glauconite (also found in Romania) and soy flour. An additional advantage of the equipment is the potential for farmers in rural areas to use organic fertilizers, such as soy flour, as blasting material.
\end{abstract}

\section{Introduction}

The role of organic farming is to produce food appropriate to the metabolism of the human body in close connection with the development of the environment, in respect for nature and its laws [1].

Combating weeds under the conditions of an organic farming, especially among vegetable crops, must be approached with great care, because it can affect soil quality, degrade organic matter and accelerate the erosion, which leads to influencing production productivity and profitability [2].

The strategies and technologies used by organic farmers vary according to crops, soils, climate and other factors. Currently, vegetable growers based largely on traditional farming practices, such as crop rotation, fertility management, high density cultivation and the use of cover crops [3].

Some of the farmers, vegetable growers in organic farming, manages weeds by combating weed seeds in the critical period of the early season or by physical suppression of weeds with plastic or natural mulch [4].

\footnotetext{
* Corresponding author: marin 43eu@yahoo.com
} 
Weed blasting is a new weed control technology, which has the potential to reduce the number of agricultural works in the context of organic farming. Some of the vegetable growers are interested in the possibility of using technical equipment that can apply organic fertilizers as abrasive materials to combat weeds and supplement the nutrition of the crops in a single pass [5].

A study based on research carried out over two consecutive years of abrasive weed control in a corn crop with granulated corn cobs has shown that the biomass of weeds can be substantially reduced and can help to maintain production, due to the fact that the cob particles (Fig.1) are valuable first because they are very absorbent, biodegradable, renewable and abrasive [6].
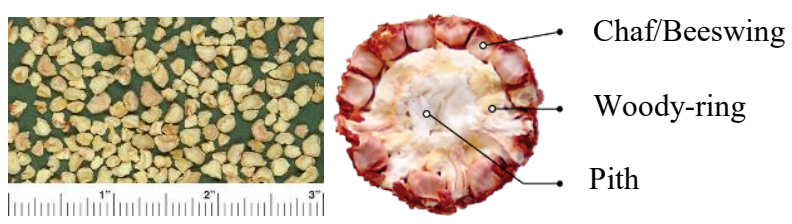

Fig. 1. Granulated corn cobs [7]

In some research papers, it is highlighted that by using FEA, which examines the behaviour of the product in contact with forces, considerable advantages are gained in dramatically reducing the costs of experimental testing and redesign. [8].

Seeking to respond to the demands of farmers who want to take appropriate measures for the correct application of natural, ecological products for combating weeds in vegetable crops through the blasting method, currently INMA in collaboration with ICDPP is conducting under a research contract with the project "Integrated system environmental management (SIM) of phytosanitary risks by complex methods of sustainable management of agroecosystems", which led to the design of a blasting equipment.

\section{Methodology}

For designing the technical equipment for weed blasting, which consists of a blasting machine connected to a compressed air compressor mounted on a frame worn on the threepoint suspension mechanism of a 45-hp tractor on wheels, it was used the SOLIDWORKS 3D CAD software, developed by Dassault Systèmes SolidWorks Corporation [9].

The PhotoView 360 tool from the SOLIDWORKS 3D CAD menu allowed you to view the product a step further and make a photorealistic image directly from the 3D CAD model (Figure 2).

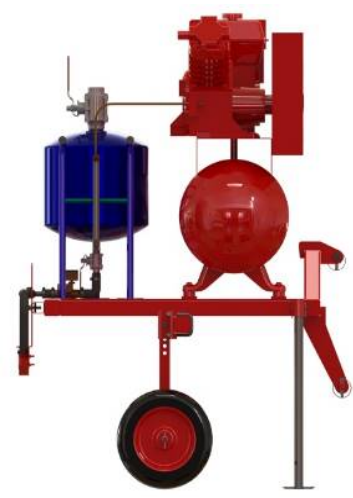

Fig. 2. Equipment for blasting weeding weeds- image taken with PhotoView 360 tool 
In the 3D geometric 3D modelling, SOLIDWORKS 3D CAD allowed both basic operations - Extrude, Loft, Rotate, Sweep - in boss and cut variants (addition and cutting) as well as more complex operations such as Wrap, Free Form, Radiate, Surface - Offset, Face - Replace, Heal, or Spline on Surface. SOLIDWORKS 3D CAD is also very well developed from the point of view of geometric references (lines, points, planes, coordinate systems, etc.) that helped the operator both as landmarks and for the correct visualization of the $3 \mathrm{D}$ model. Testing in the virtual environment of the assemblies in terms of static load resistance, finite element analysis (FEA) was performed using the SOLIDWORKS ${ }^{\circledR}$ Simulation structural simulation application, which involved importing the geometry of the model made with SOLIDWORKS 3D CAD, defining the material of each component part, defining appropriate meshing restrictions and running linear stress analysis under the effect of an applied load to determine stresses, displacements, safety coefficient and result visualization [10].

\section{Results}

Figure 3 shows a sequence from the comparison of the study analysis and results, which appears on the screen in the form of the von Mises voltage distribution, the displacement distribution, the image of the shape deformation and the safety coefficient for the welded frame of the technical abrasive weeding equipment.

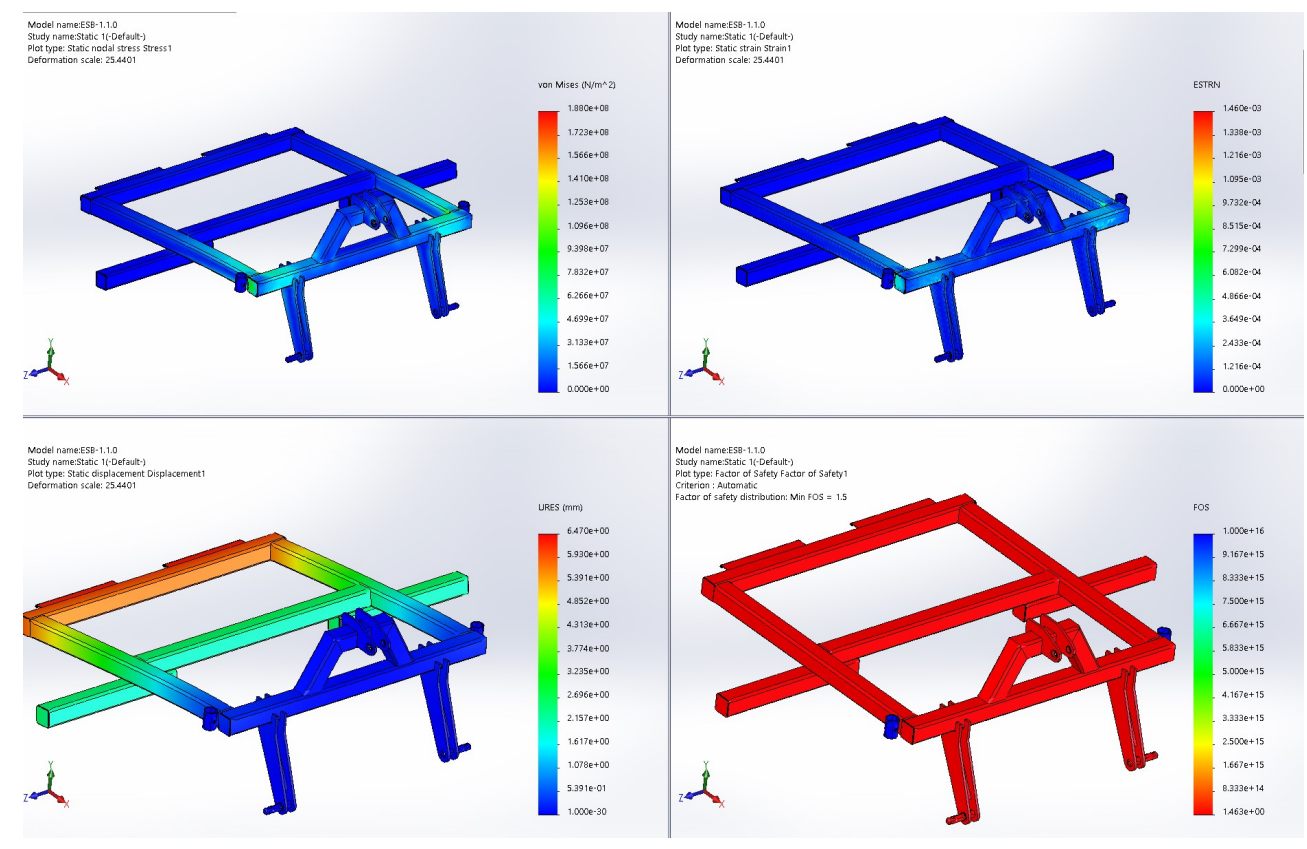

Fig. 3. Sequence that appears on the SOLIDWORKS ${ }^{\circledR}$ Simulation application screen when comparing the analysis study and results for the welded frame

At the same time, in order to carry out research on the experimental lots of SCDL Buzau in transplanted vegetable crops, which are substantially larger than weeds emerged at the time of application, the main component was subjected to the theoretical research to optimize the blasting process.

For uniform distribution of pressure and organic air-material mixture, to be used in weed blasting, theoretical researches were carried out to achieve a Venturi nozzle which 
has an extensive mark of the blasting jet and an increased speed of the abrasive by up to $100 \%$ at a given pressure.

Nozzle conceived is characterized by the flow geometry that produces a compact, controlled distribution beam in the form of a parabola of the sandblast jet and insensitive to pressure fluctuations. To perform the simulation has been used the SOLIDWORKS ${ }^{\circledR}$ Flow Simulation module, which is an intuitive Dynamics Fluid Dynamics (CFD) solution embedded in SOLIDWORKS 3D CAD [11]. Initially, was made the 3D model of the nozzle, after which were analysed the flux conditions. The finite element method was initiated by establishing the computing field, fluid subdomains, boundary conditions, and the networking. After running the simulation, it was possible to visualize the pressure and flow velocity through the nozzle (Figure 4).
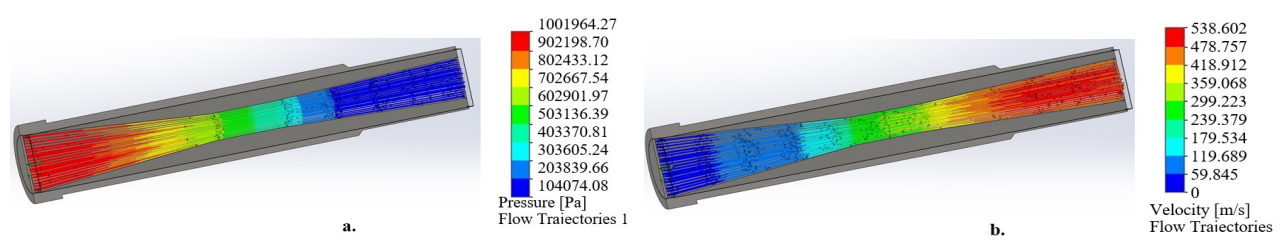

Fig. 4. Sequences of pressure (a) and speed (b) of organic air-material mixture in the nozzle

\section{Conclusions}

Studies conducted, by using CAD-assisted design software and CAE-assisted simulation, have allowed optimal design of the sub-assemblies and component parts of the weed abrasive weeding equipment.

This work can be developed using other optimization algorithms and other modelling techniques.

\section{Acknowledgement}

This work was supported by a grant of the Romanian Ministry of Research and Innovation, PCCDI - UEFISCDI, project number PN-III-P1-1.2-PCCDI-20170301/28PCCDI/2018.

Also, this work was supported by a grant of the Romanian Research and Innovation Ministry, through Programme 1 - Development of the national research-development system, subprogramme 1.2 - Institutional performance - Projects for financing excellence in RDI, contract no. 16PFE.

\section{References}

1. M. Lähdesmäki, M. Siltaoja, H. Luomala, P. Puska, S. Kurki, Journal of Rural Studies, 65, 152-160, (2019)

2. Jerkins, D, and J. Ory, National Organic Farmer Survey and Listening Sessions. Organic Farming Research Foundation (www.ofrf.org), 128, (2016)

3. B.P. Baker and C.L. Mohler, Renewable Agriculture and Food Systems 30, 418-427, (2015).

4. B. Brown and E.R. Gallandt, Renewable Agriculture and Food Systems, 1-7, (2017)

5. S. E. Wortman, Crop Protection, 77, 157-162 (2015)

6. M. Erazo-Barradas, C.N. Friedrichsen, F. Forcella, D. Humburg, and, S.A. Clay, Renewable Agriculture and Food Systems 1-8, (2017) 
7. $* * *$ http://www.greenproducts.com/greentru/corncob-products/

8. S.Șt. Biriș, N. Ungureanu, D. Cujbescu, INMATEH Agricultural Engineering, 57, 261270, (2019)

9. $* * *$ https://www.solidworks.com/product/solidworks-3d-cad

10. G. Gheorghe, C. Persu, I. Gageanu, D. Cujbescu, Proceedings of the $46^{\text {th }}$ International Symposium ATAE, 79-86, (2018)

11. *** https://www.solidworks.com/product/solidworks-flow-simulation 